\title{
on_education
}

Journal for Research and Debate

\section{interpreting the idea of the anthropocene, and its relevance to education}

\author{
Michael Bonnett
}

The increasing reference in the literature of education to the idea of us having entered a new geological epoch - the 'Anthropocene' - is telling in two important ways: one good and the other bad. It is good in the sense that it encourages a full acknowledgement that much environmental degradation is anthropogenic. Species extinction on a grand scale, pollution of the atmosphere and the oceans, habitat destruction and global heating are down to the activities of human beings.

The increasing reference in the literature of education to the idea of us having entered a new geological epoch - the 'Anthropocene' - is telling in two important ways: one good and the other bad. It is good in the sense that it encourages a full acknowledgement that much environmental degradation is anthropogenic. Species extinction on a grand scale, pollution of the atmosphere and the oceans, habitat destruction and global heating are down to the activities of human beings. We are alerted to the fact that we are leaving the relatively stable and benevolent Holocene epoch that has lasted some 11,500 years and entering a period of huge climatic uncertainty in which the Earth's current equilibrium is being disrupted - maybe to the extent that irreversible processes have been set in train that will result in ever more severe weather events and possibly the extinction of humanity. Looking on the bright side, maybe there is still time to avoid catastrophe through changes in human behaviour, but if so, these changes will have to be radical and swift. Educationally, a key point is that it is time for humankind to take full responsibility for its actions with regard to the environment, both in terms of seeking to mitigate the deleterious effects of past behaviour and to ensure that future behaviour causes no further damage.

But the idea of the Anthropocene can also have a negative impact. It can reinforce precisely those deep motives and perceptions that have led us into our current environmental predicament. It is interesting - but of course wholly unsurprising - that one of the chief sources of wider engagement with the idea of the Anthropocene is that it heralds a challenging time for the wellbeing of humanity. In this sense its currency as a notion is highly anthropocentric. Furthermore, by concentrating the focus onto the effects of human agency in the environment, elevating their status in geological terms, it can reinforce a form of human self-aggrandisement that backgrounds the significance of 'natural' agency. This sits well with the increasing dominance of what I have dubbed a 'metaphysics of mastery' in which everything is subject to the assertion of the human will (Bonnett 2004; 2015). Here, culturally, we are inserted in a reality in which increasingly all that we encounter (including, and perhaps especially, the natural world) appears in terms of its potential to serve or frustrate our will. And anything that is refractory to our demands becomes viewed as 'useless' (and therefore of no value), or as standing in need of reengineering. Arguably, this aggressively instrumental frame of mind, that in turn has initiated the development of technologies of ever- 
increasing power, is the root cause of the despoliation of the natural environment that we have wrought and that is now rebounding on us. Where the metaphysics of mastery holds sway everything appears essentially as a resource, its meaning and value being determined by its location in the chains of calculative reason that we generate in the service of our self-given purposes and demands. Here, no space is left for things in nature to exist as natural, possessing their own being that incorporates their own agency and intrinsic value. Nature qua nature is becoming invisible in our everyday lives. As we might put it, we have lost our ability to hear nature's 'voice' - its part in shaping the places that we inhabit and its significance for any environmental decision-making that we undertake.

This brief analysis has major implications for education in a time of radical uncertainty of the kind alluded to above. Despite the best - and ongoing - efforts of discursive science 1 , our current knowledge base remains inadequate to predicting in detail what the longer term future of the environment will be. Natural processes are just too complex and spatially and temporally extensive. This insufficiency means that ambitions to manage the environment on any grand scale, often through the development of new technologies, are misplaced. Indeed, much of the history of human intervention in natural processes has been one of unintended consequences. Hence while discursive science has a role in preparing us for what the future holds, its limitations - and those of the technologies that it spawns - must be recognized.

And there are further dangers associated with allowing it to dominate education, for example, in ways encouraged by advocates of prioritizing STEM programmes in public education in the US and elsewhere. The educational problem here is that a strong theme running through classic experimental science has been that of controlling nature in the interest of human utility and hence the implicit notion of nature informing the whole enterprise is again that of resource. For example, at its inception Francis Bacon advocated that in the new science nature should be 'hounded in her wanderings', 'bound into service', have her secrets 'tortured from her', and while one would be unlikely to encounter such stark language today, it remains the case that areas of science are still willing to intervene very aggressively in the lives of living organisms and in natural processes in the pursuit of anthropocentric objectives. This raises a critical question for education in our time of extensive environmental degradation and uncertainty (whether or not now we term it 'Anthropocene'): what would be a 'right' relationship with nature and how do we best 'know' nature? Answers to these questions would be central to future policy and conduct. As a (perhaps the only) species that can be held responsible for its actions, and as the species whose actions have had such a disastrous impact on the well-being of so many other species (e.g. 'exploding human consumption' has resulted in losses in vertebrate species that averaged 60\% between 1970 and 2014 (WWF 2018) and the near extinction of many apex predators), its future conduct toward the natural world is surely an important educational matter on moral grounds as well as prudential ones.

This raises the question of ecological justice in contradistinction to social justice as an important orientating principle in personal, social and moral education. This conception of justice questions the rampant 'human supremacism' that currently pervades our ideas of how the Earth's resources should be distributed, claiming that the needs of inhabitants of the natural world must be properly taken into account. 2 In practice this will have implications not only for how we should view levels of human consumption, but also levels of human population growth. Even from a purely anthropocentric perspective, on some estimates the ecological carrying capacity of the planet is already being exceeded by a factor of three or more. 3 While any such estimates must be subject to a number of qualifications regarding, for example, assumed levels of consumption and the impact of 
future technologies, unforeseeable natural events, etc., they give a broad idea of the scale of the problem, and when the current aspirations of developing nations are taken into account this will only become more acute. Ecological 'footprint' is highly significant to ideas of sustainability, but so, too, must be the number of feet. Although politically contentious, the latter cannot be decoupled from the issue of sustainability. If education is to contribute positively to our current and future environmental predicament, it is difficult to see how it can avoid the issue of responsible family planning.

Amongst other things, ideas of ecological justice raise an important underlying issue: that of nature's intrinsic value. This is also relevant to the previously raised key questions of how we relate to, and know, nature. The idea of nature itself having moral standing presupposes its possessing intrinsic value (if it only had instrumental value its moral relevance would be restricted to its contribution to human well-being) and recognition of this is clearly central both to what could count as a proper relationship with nature, and also to aspects of what would be involved in knowing it. Over recent decades there have been attempts to establish nature's intrinsic value by bridging or denying the traditional ontological divide between humanity and the rest of nature. If this can be achieved, nature would be due the same (or parallel) respect accorded to human beings. Certainly, it could no longer be regarded purely as a resource, and heeding its 'voice' would form an integral part of our relationship with it.

I will say more about this idea of its voice presently, but on the issue of its ontological parity with humankind, there have been a number of offerings. These include the idea that functionally all members of the biotic community are interdependent and therefore of equal value and that through delineating and protecting themselves as individuals and species express a valuing of their lives that demands respect (e.g. Taylor 1986; Rolston III 1999). Other views argue that if we would only abandon anthropocentric notions of consciousness, and for example adopt 'enactivist' ideas of agency, cognition and learning, we would see that all living (and in some cases non-living) things can be regarded as 'conscious' and deserving moral regard (e.g. McDaniel 1986; Affifi 2017). While such attempts to overcome the human/nature dualism are energized by the worthy ambition of elevating nature's interests and engendering a proper respect for aspects of the natural world, it seems to me that they result in doing insufficient justice to them. The danger here is a form of reductionism that corrodes a feature essential to the being of nature: its self-arising otherness - that in turn, can only occur in the space that is human consciousness, or its equivalent. This self-arising otherness imbues many significant aspects of nature that are in danger of being effaced by preoccupation with human agency invited by the idea of the Anthropocene, and that are essential to entering a relationship with nature that is adequate to shaping future behaviour. Let me give an illustration of these qualities of nature by means of a brief phenomenological vignette. 4

Suppose on a country walk we were to come across a small river wending its way silently through the landscape. Overhanging the dark waters is an old willow, its fissured trunk leaning out at a precarious angle, its searching roots revealed by the eroding bank. In the play of sunlight and cloud shadow and a gentle breeze, its gently fluttering leaves glitter silver and green and its bark, home to delicate moss and lichen growth, displays strange and ever-changing shapes. Below a slow stream of bubbles arising from invisible depths breaks the surface of the water to disturb the poised insects that, gathered in the shade of the tree, tread the water making the tiniest of indentations. And so forth.

It seems to me that a number of salient features of nature are displayed by everyday experiences of 
this kind. These include self-arising nature as occurring in unique places that are redolent with mystery and motion. There is revealing and withholding, things seen and not seen - yet whose potentiality is felt and draws us in. There is agency and anticipation, integrity and value - of which we are not the author, but if sufficiently attentive, are rather the recipients. The inhabitants of this place (including those we normally consider non-sentient) occur through an interplay of mutual participation in each other. Without the flowing water, the insects, the lichen, and so forth, the willow cannot 'presence' in the way that is does - and vice versa. In this sense a mutual sustaining is in play that upholds the occurring of the inhabitants of this place, and is itself a place-making. A sustaining in which, we, too, participate if we are attuned to its otherness. By being open to and responding to the manifold address of this place our lives are refreshed and enriched, our consciousness, that by its intentional nature always reaches beyond itself, is fulfilled. And through allowing consciousness to be the place where nature can occur in this way, we can break out of the metaphysics of mastery. Instead of a life increasingly preoccupied with the artefactual and where everything is experienced in terms of demand, we can gift the gift of the given.

To the extent that it is plausible that this vignette is suggestive of a frame of mind or way of being that expresses an authentic acquaintanceship with, and knowledge of, nature 5 - one that needs to be set alongside and perhaps to re-orientate scientific endeavours - clearly it has important educational implications. For example, its essentially poetic character requires the valuing and nurturing of a sense of wonder, and a re-sensitizing of the senses that allow free entry into a world of mystery and spontaneity.6 It reveals the enervating effects of a highly pre-specified curriculum that by its nature obstructs open engagement in learning and is the bane of being there in a place, alert to the spontaneous address both of what announces itself and what is withheld. In order to move beyond the illusory idea that our environmental crisis is one susceptible of technological fixes, we need to gain a better understanding of ourselves and our place in nature. This is achieved through intimate acquaintance of the kind described above rather than by abstract calculation.

By way of conclusion, I suggest that turning to a phenomenology of nature reveals a key feature of nature: its ontological otherness and therefore its epistemological mystery. Participating in this is central to a proper relationship with, and knowledge of, nature. From this follows an authentic understanding of nature, its moral standing, and its relationship to human well-being that are all key to education in our current time - even if, as may be, that time is running out and we must consider the possibility of education without a future. Whatever turns out to be the case here, another thought arises. Maybe this is just too fanciful, but perhaps in general terms the above account invites an interpretation of the Anthropocene in which attention is drawn not to the geological impact of an aggressive human will, but rather to a new metaphysical epoch in which humanity's potential for participating in the being of things - allowing them to occur in the nobility of being themselves will be realized.

\section{References}

Affifi, R. (2017). The metabolic core of environmental education. Studies in Philosophy and Education, 36(3), 315-332.

Bonnett, M. (2004). Retrieving nature. Education for a post-humanist age. Oxford: Blackwell.

Bonnett, M. (2012). Environmental concern, moral education, and our place in nature. Journal of Moral Education Special Issue: Moral Education and Environmental Concern, 41(3), 285-300.

Bonnett, M. (2015). Sustainability, the metaphysics of mastery and transcendent nature. In H. Kopnina and E. Shoreman-Ouimet (eds.), Sustainability: Key issues. London: Routledge Earthscan. 
Bonnett, M. (2017). Environmental consciousness, sustainability, and the character of philosophy of education. Studies in Philosophy and Education, 36(3), 333-347.

Daily, H., Ehrlich, P. \& Ehrlich, A. (1994). Optimum human population size. Population and Environment, 15(6), 469-475.

Kopnina, H., Washington, H., Gray, J. \& Taylor, B. (2018). The future of conservation debate: Defending eco-centrism and the nature needs half movement. Biological Conservation, 217, 140-148.

Rolston III, H. (1999). Ethics on the home planet. In A. Weston (ed.), An invitation to environmental philosophy. Oxford: Oxford University Press.

McDaniel, J. (1986). A feeling for the organism: Christian spirituality as openness to fellow creatures. Environmental Ethics, 8, 33-46.

Schinkel, A. (2017). The educational importance of deep wonder. Journal of Philosophy of Education, 51(2), 538-553.

Taylor, P. (1986.) Respect for nature: A theory of environmental ethics. New Jersey: Princeton University Press.

UN (2017). World population prospects: The 2017 revision. Key findings and advanced tables, p. 2 (New York, UN Department of Economic and Social Affairs). Retrieved 15.1.2019

Washington, H. (2018). Education for wonder. Education Sciences, 8, 125. https://doi.org/10.3390/educsci8030125

WWF (2018). The living planet report - 2018: Aiming higher. Gland: World Wide Fund for Nature (WWF)

\section{Recommended Citation}

Bonnett, M. (2019). Interpreting the idea of the Anthropocene, and its relevance to education. On Education. Journal for Research and Debate, 2(4). https://doi.org/10.17899/on_ed.2019.4.2

\section{Download PDF version}

Do you want to comment on this article? Please send your reply to editors@oneducation.net. Replies will be processed like invited contributions. This means they will be assessed according to standard criteria of quality, relevance, and civility. Please make sure to follow editorial policies and formatting guidelines.

\section{michael bonnett}

Michael Bonnett is currently an independent scholar who has held senior teaching and research positions in the UK universities of Cambridge, London, and Bath. He has published widely in the field of philosophy of education giving particular attention to ideas of learning, thinking, personal authenticity and the character of the teacher-pupil relationship in education. More recently, his focus has been on aspects of sustainability and environmental education.

1. By 'discursive' here, I refer to the idea that, rather than dwelling with things, all science runs on from one thing to another through categorizing them and framing hypotheses and explanations. 
2. See Kopnina et. al. (2018) for a spirited defence of nature's needs.

3. The UN 2017 revision of World Population Prospects (p.1) gives a human population of 7.6 billion for 2017 with a projected population of 9.8 billion for 2050. Daily et. al. (1994) argued that an ecologically sustainable population is $1.5-$ 2 billion.

4. See Bonnett $(2012 ; 2017)$ for more developed accounts.

5. I use the term 'authentic' here to denote an acquaintanceship or knowledge that is true to - genuinely reflects - the primary reality or selfhood of the things with which it engages.

6. See Anders Schinkel (2017) and Haydn Washington (2019) for discussions of the educational relevance of a sense of wonder. 